\title{
Contextual Enablers and Hindrances of Girl Child Participation in STEM Education in a Kenyan County: A Case Study
}

\author{
Kelonye Festus B..$^{*}$, Odeo Isaac Ipara ${ }^{2}$, Ooko Selline ${ }^{3}$, Nashon \\ Samson $^{4} \&$ Juma Godfrey S. \\ ${ }^{I}$ Department of Biological and Environmental Sciences, Kibabii University \\ ${ }^{2}$ Faculty of Education and Social Sciences, Kibabii University \\ ${ }^{3}$ Department of Pure and Applied Sciences, Masinde Muliro University of Science and Technology \\ ${ }^{4}$ Department of Curriculum and Pedagogy, University of British Columbia \\ ${ }^{5}$ Department of Mathematics, Kibabii University
}

\begin{abstract}
In Kenya, student performance in sciences and Mathematics is still low compared to artoriented disciplines. The poor performance has affected not only the Girl child's interest in these disciplines but also the number of girls that take STEM-oriented programs at tertiary levels. Several mitigating measures have been enacted although the situation has not changed much. This paper reports a study that explored contextual enablers and hindrances of Girl Child participation in STEM education in a Western Kenyan county. The study employed a case study approach by administering structured questionnaires, interview schedule and focused group discussion guide for data collection. The data were analyzed using both quantitative and qualitative methods and revealed that: 1) lesson development that connected science concepts to activities in the local context motivated and improved girl child's participation and performance in contextualized learning activities and 2), familiarity with the materials and tools used in planning and implementing contextualized learning activities evoked the girl child's enthusiasm and courage to exchange knowledge and ask more curiosity focused questions. Also revealed were hindrances including: 1) teachers' initial training that did not prepare them for this way of teaching and it was not and has not been modeled for them during their pre-service education or the ongoing professional development workshops; and 2) the exam driven nature of the curriculum serving as a hindrance to teacher innovation and creativity in instructional techniques. The study recommends a more creative and innovative teacher training system and focused research to monitor girl child participation and performance in STEM education.
\end{abstract}

Keywords: Contextualized learning; Girl Child, STEM education; performance

\section{Introduction}

\section{Background to the study}

Contextualized Teaching and Learning (CTL) can be interpreted differently by different scholars. However, in the study discussed in this paper, we employed Hull's (1993) contextual learning theory to investigate the girl child participation in STEM Education activities in a Western Kenyan County. According to Hull (1993) and as conveyed in Anderson and Nashon (2013) as well as Nashon and Madera (2013), contextual learning involves the mind in seeking meaning in a context as well as relationships that make sense and resonate with one's sociocultural background. Thus, as Nashon and Madera (2013) elaborate, contextual teaching and learning of science and for that matter STEM-based disciplines, "means using local contexts to explain scientific[/STEMbased] concepts or phenomena by showing how the concepts can be applied in solving local everyday problems" (p.2). In this way, students engage in active learning since understanding is linked to the local environment, which they know and can connect what they know with new knowledge from the learning process (Hudson \& Whisler; 2007). CTL has been associated with student engagement with and performance in STEM education (Spencer, Sunm \& Ivry; 2006). However, many school curricula in Kenya still follow the traditional 
colonial examination-driven formats where contextualizing teaching and learning activities is unappreciated (Anderson \& Nashon, 2013; Nashon \& Anderson, 2013; Nashon \& Madera, 2013). Moreover, it is well documented this exam-driven instruction, which encourages memorization as a dominant way of learning, has not been useful to the girl child. Hence, girls have continued to register poor performance in STEM education (Ngesu et al., 2012). Of course, boys have generally been observed to perform better than girls (Kashu, 2014).

Several factors have been observed to contribute to the girls' poor performance in STEM education. These factors vary from socio-economic, socio-cultural (Lanyasunya, 2000) to teacher characteristics (Bagaka, 2011). This state of affairs undermines the progress to achieving Kenya's vision 2030 targets for sustainable development goals on reducing inequalities and access to education (DU, 2016).

In Kenya, student performance in the sciences and Mathematics is still low compared to art-oriented disciplines with girl child still underperforming in these subjects (Musau \& Abere, 2015). The poor performance has affected not only the Girl child's interest in these disciplines but also the number of girls that take STEMoriented programs at tertiary levels (Mbirianjau, Chege \& Oanda, 2019). Kenya's education system is demarcated into multiple structural levels that can be described as preprimary ( 3 years); primary school science ( 8 years), secondary school (4 years) and university (At least 4 years) for an undergraduate degree (UNESCO, 2016). While pre-primary education should be about allowing the children to explore and experience their local environment guided by the teacher, and engage in creative experimentation and exploration during "play" (Beattie, 2015), the fact is, not much of this is happening given that the $\mathrm{K}$ - curriculum is formalized where children are prepared for the future world of grades $1-8$ characterized by exam driven curricula with memorization as the dominant learning methodology (Seline et al., 2018).

Despite efforts to enhance girl-child participation, access and performance in STEM education, the situation has not changed (Onsongo, 2006; Hooker, 2017). Systematic Gender stereotyping with regard to participation in STEM education is still commonplace (Mbirianjau, Chege \& Oanda; 2019). Teachers' negative attitudes and poor approaches to teaching that are insensitive to girls' needs have also been noted to contribute to girls' disinterest in STEM education (Benitez-Herrera et al, 2019). In addition, deficiency of real-life contextual approaches and resistance to change by teachers have further been observed to contribute to the lack of pedagogical innovations (Thibaut et al., 2018). Teaching approaches and strategies have a significant impact on academic access, retention and performance of both boys and girls (Jia, et al, 2017; Sithole et al., 2017).

The lack of real-life approaches in teaching has contributed significantly to girls' underperformance in STEM subjects. Poor attitudes of teachers and unapproachability have also been observed as contributing factors to poor performance (Hoy \& Spero, 2005). In addition, teaching approaches and teacher characteristics have been identified as retrogressing girl child performance in STEM education in Kenya (Mbirianjau, Chege \& Oanda; 2019). This raises the need to enhance access to education and participation by girls in STEM education through the deployment of contextualized pedagogical tools. Learners at the primary school level thrive in an environment that depicts cultural and traditional family setups that can be an important contextual reference to making STEM education more meaningful and relevant as they relate the natural and socio-cultural phenomena (Virvou, Katsionis \& Manos; 2005). The fourth sustainable development goal of the United Nations; has specific and well-defined targets that include equal access for learners of all genders to quality early childhood education, development of relevant skills for work; inclusion and equality among others (Assembly, 2015). In this regard, the importance of empowering girl learners with early childhood skills, attitudes and knowledge in STEM education cannot be overemphasized. We argue that the application of traditional contexts regarding what the girl child embraces out of school in teaching will most likely enhance her capacity to link real-life experiences and constructs with science teaching in class. 


\section{Problem Statement}

Kenya, like other African countries, is currently facing poverty, unemployment, poor infrastructure, destruction of the environment and many health issues (Maiyo \& Bawane, 2011). This comes in the backdrop of a myriad of challenges facing girl child education in Africa characterized by inequality and challenges of access (Offorma, 2009). Higher primary school dropout rates by girls have been observed in one of Western Kenya's counties (Wangila, 2019). This has been attributed to Socio-Cultural factors including parental attitudes, early pregnancies and marriages, insecurity, and high poverty levels (Lanyasunya, 2000). There is a need to enhance equitable, access and performance of the girl child to STEM education in order for Kenya to realize sustainable development. Attempts to address this need have encountered challenges including the problem of female learners staying away from STEM subjects and even dropping out altogether (Wajngurt \& Sloan, 2019).

As has been demonstrated in case studies elsewhere (e,g, Nashon \& Anderson, 2013; Nashon \& Madera, 2013; Nashon et.al.,2021) contextualizing teaching and learning consistent with Hurl's (1993) theory of learning discussed earlier in this paper, can be an enabling approach to achieving girl child participation and success in STEM education in Kenya.

\section{Objectives}

The main objective of this study was to investigate the enablers and hindrances of the girl child's engagement with classroom-based discourses on STEM-related topics and STEM education in general. This objective was addressed through the following specific objectives:

(i) Identify teacher characteristics that affect female learners' participation in STEM learning activities

(ii) Examine the extent to which contextualized pedagogy and related learning tools can enhance the girl child's participation and improved performance in STEM learning activities.

\section{Literature Review}

Studies by Murphy \& Beggs (2001) described the impact of teachers and positive attitudes to science as critical for female learners' participation in STEM. Scientific Knowledge and skills of science teachers has been observed to impact on learner participation in science subjects as investigated by Cheung et al., (2018) with the teachers' conduct during the teaching process affecting learners' attitudes (Den-Brok et al., 2005). More practical work in teaching the sciences, attribution of importance to science learning, balanced gender-based motivation, and a dynamic curriculum able to address scientific knowledge acquisition are just but a few of other characteristics that can enhance girl-child participation in STEM education (Murphy, Beggs and Carlisle; 2003); Thompson \& Soyibo (2002); Gömleksiz (2012); Kim et al., (2015). Studies have revealed that enhancing women's participation in STEM education is a current need in Kenya that has to be addressed through drastic reforms in order to accelerate sustainable development (Lewin, 2015; UNESCO, 2016). Other studies that have investigated student learning as framed within local contexts in Kenya have been around learning science through local manufacturing industries known as "Jua Kali" whose products are ubiquitous in every Kenyan household and very familiar to both boys and girls. Noteworthy, among the many Jua Kali production activities and products from which scientific phenomena were investigated was the charcoal stove which was determined to: a) be ubiquitous and used daily by students in most households across Kenya; b) use natural resources including charcoal, although varieties are being produced that use sawdust, kindlers, or agricultural residues - all of which have limited sustainable supply; c) involve vigorous innovations in the Jua Kali regarding the production of the most efficient charcoal stoves; and d) have very significant implications on forests and other rare plant and tree species sustainability. 
According to Beru et al. (2014), the connection between sustainability and the production of such stoves has profound implications on Kenya's wood fuel sources. As Anderson and Nashon (2013) and Nashon et al. (2021) report in their case studies 1) students understood science better in a canonical sense when instruction used local contexts to mediate curriculum; 2) students were provoked and inspired to make a critical assessment of their prior learning strategies and habits by fascinating and contextualized experiences; and 3) students became acutely aware that the learning strategies they used were a consequence of the nature of the prevailing curriculum and lack of pedagogical models that make science relevant (Nashon, 2013; Nashon \& Madera, 2013; Nashon et al., 2015). Also, the studies revealed how this way of student learning impacted the teachers in various ways including: 1) The teachers experienced a conflict between their literal and rigid interpretations and strict adherence to the official curriculum and the students' desires to understand scientific phenomena embedded within their local environment; 2) The science teachers' inability or ability to sustain students' motivation to understand science through local contexts in part depended on initial teacher training; and 3) Implementation of the contextualized science reduced the gulf that often hindered free student-teacher dialogue due to the teachers' endeavors to maintain science and teacher statuses (Anderson, et. al., 2015; Nashon, 2013; Nashon \& Anderson, 2013b). Based on this literature review, the need for exploring the contextual enablers and hindrances of the girl child participation in STEM education became critical and hence the study this paper reports.

\section{Methods}

The study adopted a descriptive research design with a case study approach over a Western Kenyan County. Purposive sampling was employed targeting 50 public primary schools 50 private primary schools. One hundred (100) head teachers, 200 science teachers, 400 class 8 pupils were interviewed. Data was collected using questionnaires and observation schedules examining teacher and learner characteristics. The questionnaires were demarcated in two sets, one for teachers and the other for learners and targeted sessions for mathematics and science subjects. The learners' set included a self-evaluated assessment that ranked their understanding of the subject thought for that specific lesson. Data was described statistically and presented in tables and charts. We statistically determined the relationship between selected teacher attributes and the performance of the learners. Multiple regression analysis was carried out targeting four variables, Professional training, experience, gender, and level of training respectively. The regression targeted 84 mathematics teachers and 84 female learners' responses purposefully sampled from a total of 400 learners' responses. The binary responses were interpreted as "yes" and "no". For example, trained or not, male or female, trained to diploma level or not respectively. Binary logistic regression approach was adopted to determine $\mathrm{p}$ values from categorical variables.

\section{Analysis and findings}

Teacher characteristics that affect female learners' participation in STEM were identified. The study revealed that there were more male teachers for STEM than female teachers at $(54.6 \%$ vs $45.4 \%)$ respectively. Figure 2 below shows the level of training of the teachers interviewed. It can be seen that most teachers were trained at the diploma level constituted $41 \%$ and mainly specialized in early childhood education (99\% of the diploma trained teachers). $5 \%$ of the teacher respondents had degree qualifications. Teacher progression from lower training levels was evident with $98.5 \%$ of the diploma trained teachers having started at elementary professional teaching certificate (p1). However, 38\% of the teacher respondents had the highest training level of P1 and did not pursue further training. The study observed that at least $16 \%$ of the teacher respondents were trained to an ordinary level with no professional teaching certificates and all were located in private schools.

\section{Gender}

Figure 1 below shows the gender of the respondents. The male gender is observed to be more represented compared to the female gender where $45.4 \%$ of the teacher respondents were female compared to their 
counterparts at 54.6\%. The study finds capacity gaps in terms of female teachers of STEM over the area of study.

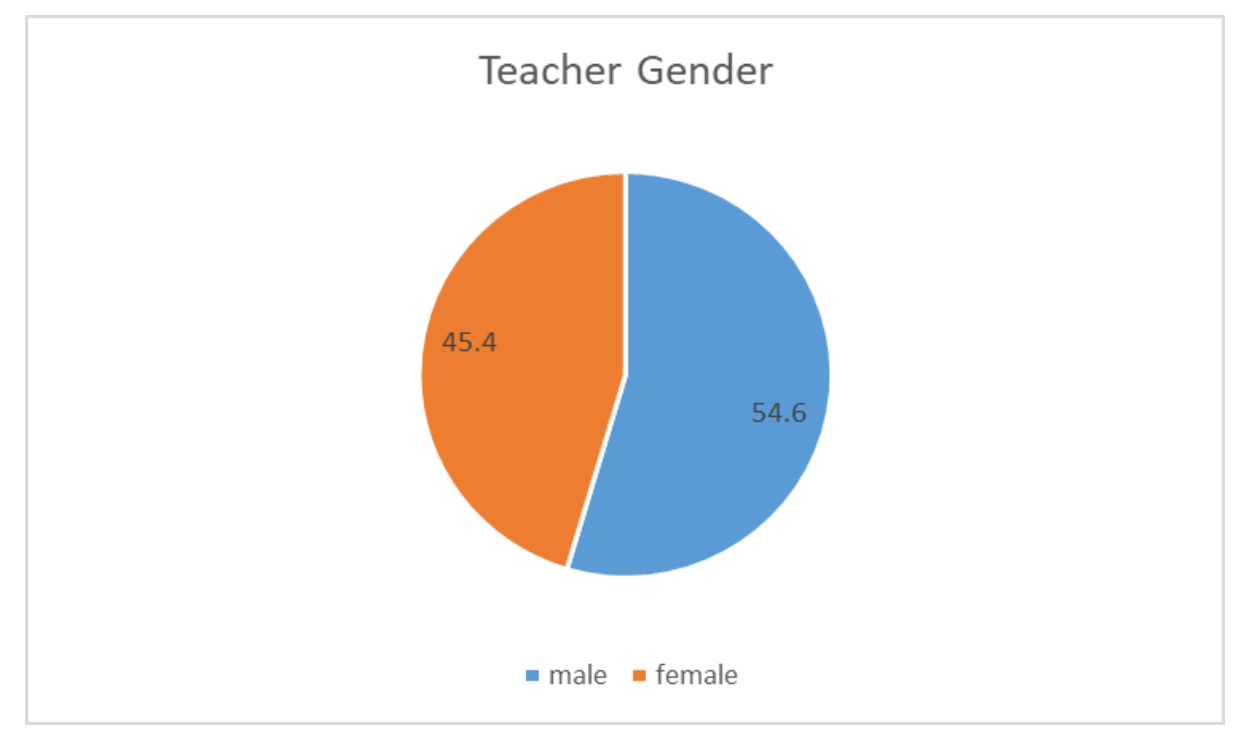

Figure 1. Gender of the teacher respondents

\section{Level of Training}

Figure 2 below shows level of training of teachers over the area of study. It can be observed that $41 \%, 38 \%$, and $5 \%$ were trained to Diploma, P1, and degree level respectively. The results of the investigation revealed that $16 \%$ of the respondents did not have any professional training. Consequently, the study found out that the training levels of primary school teachers were mainly P1 and Diploma.

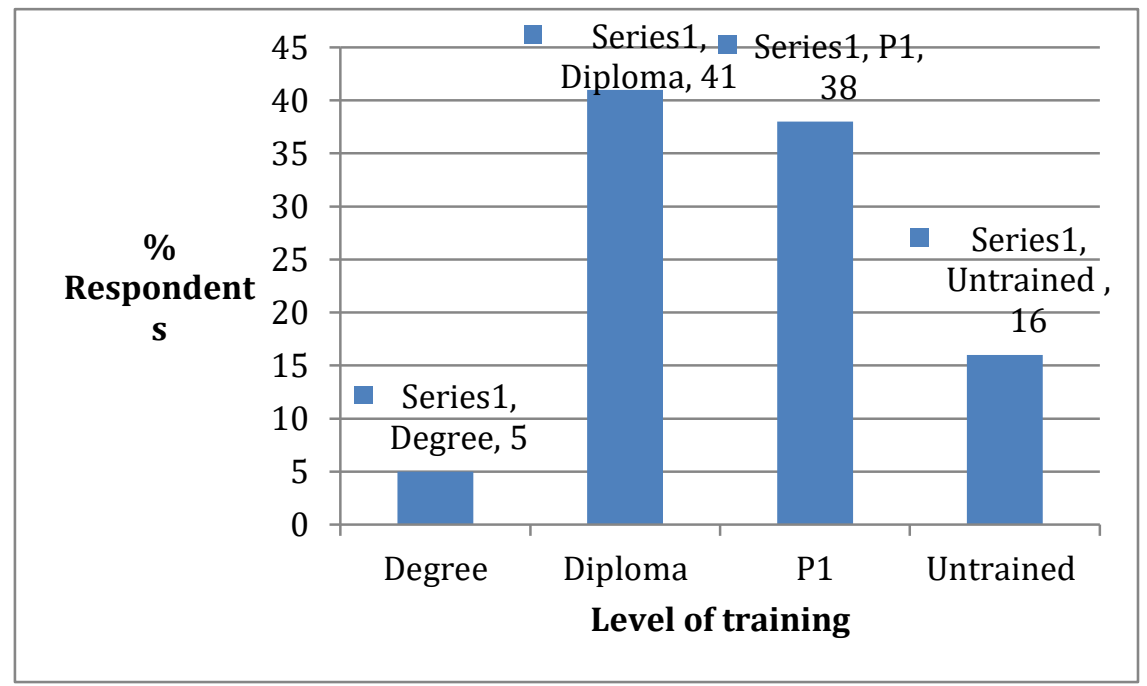

Figure 2. Level of professional training 


\section{Teaching Experience}

Teaching experience in years was examined. Figure 3 below shows years of experience by teachers interviewed. $75.4 \%$ were observed to have more than 10 years experience while $24.6 \%$ had less than 10 years experience respectively. The study also found out that $74.6 \%$ of teachers in public schools were more experienced than those in private schools. $89.7 \%$ of teachers in private schools were observed to have less than 10 years of experience respectively.

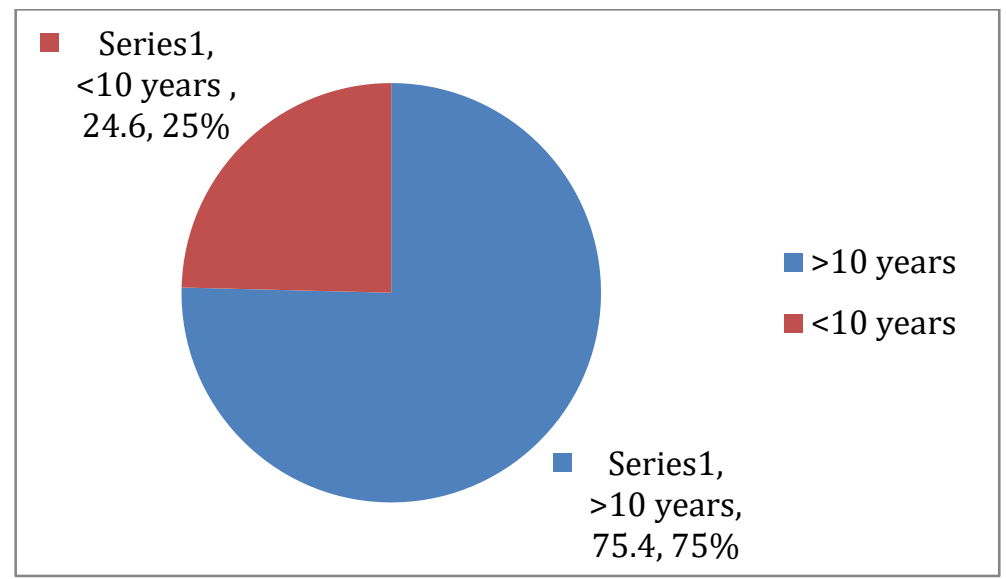

Figure 3. Experiential teaching

\section{Learners Gender}

Results of the gender affiliation of the learner respondents were reported. Figure 4 below shows the gender composition of the learners. It can be observed that 58.20 percent were of male gender while $41.8 \%$ of female gender respectively. This was attributed to unequal participation of girls in STEM subjects and school dropouts.

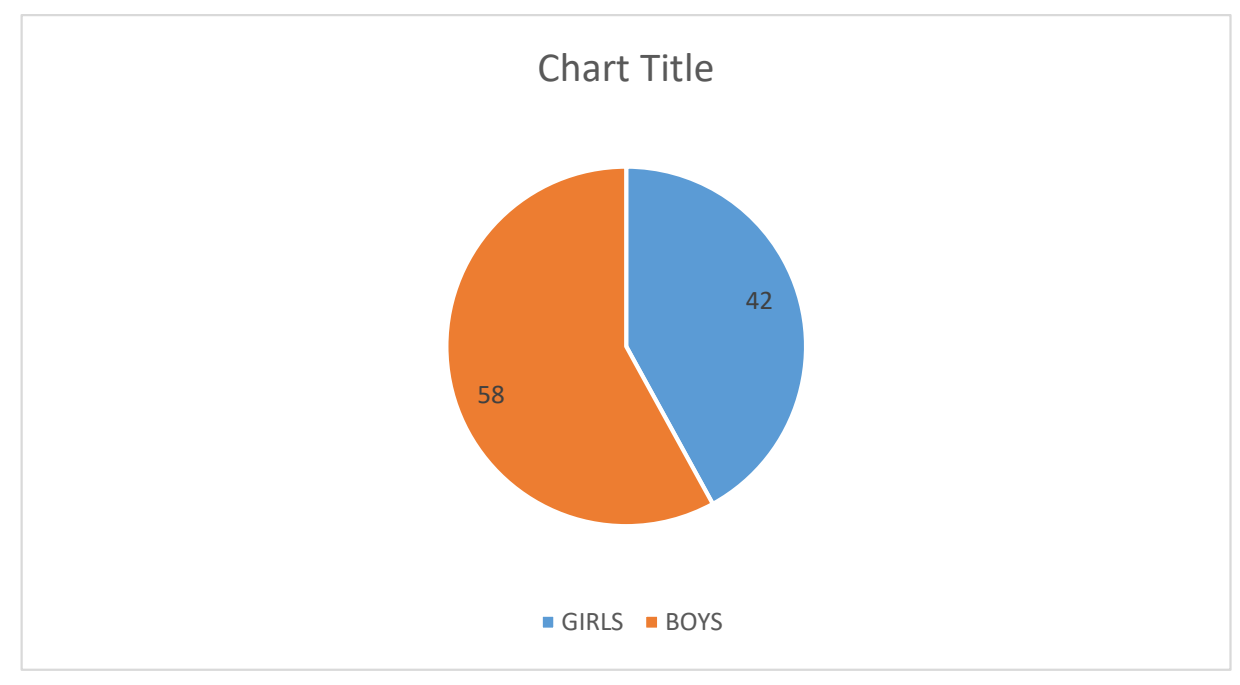

Figure 4. Gender of learners 


\section{The statistical relationship between teacher characteristics and performance}

Table 1 below shows the binary logistic regression results for the teacher attributes examined in this study. Results show that the mean score in mathematics for girls assessed is $55.78 \%$ with a minimum score of $3 \%$ and the maximum score of $97 \%$. There exists a positive and statistically significant relationship between years of experience, professional training, and gender of the teachers to performance. The study finds that training to diploma or higher levels in primary school teaching has an impact on students' performance that is not statistically significant.

Table 1. p values from binary logistic regression

\begin{tabular}{|l|l|l|l|l|}
\hline Variable & Yes & No & $\%$ & P value \\
\hline Experienced (exp) & 63 & 21 & 75 & 0.003 \\
\hline Professionally trained(pt) & 71 & 13 & 84.5 & 0.002 \\
\hline Level training (It); At least Diploma & 39 & 45 & 46.4 & 0.080 \\
\hline Gender & 55 & 45 & 46.2 & 0.025 \\
\hline
\end{tabular}

In addition, $12 \%$ of science teachers in public schools were of the opinion that most girls cannot do well in STEM while $38 \%$ of their counterparts in private schools had an opinion that girls cannot do well in STEM subjects at all. Contextual Pedagogical assessment revealed that $20 \%$ of teachers used household chores to illustrate teaching concepts out of which at least half had a minimum training level of diploma in early childhood education. This led the researchers to deduce that enhanced training in teacher education would most likely give better contextual learning outcomes for girls in STEM. Girls were observed to be more responsive than boys in classes where household chores were used for contextual illustrations. Therefore, the usage of household chores as contextual tools in teaching was observed to give better learning outcomes for girls than traditional teaching approaches.

The study also observed that at least $30 \%$ of the girl respondents felt that STEM teachers employed unfriendly teaching approaches in STEM as their demotivation while $4.1 \%$ attributed biased opinion about girls by teachers as their major discouragements. The need for teachers to reexamine their attitudes to female learners in STEM was identified.

Learning attitudes by learners were examined. The study identified $2.2 \%$ of girl respondents who attributed their poor attitudes in science subjects to sexual harassment by male teachers. Moral and professional discipline was therefore observed to be imperative in handling female learners and improving female learners' attitudes in STEM. The study is of the opinion that Pedagogical approaches have to be continuously re-examined to address emerging girl child needs in education. The study observed existing gender disparities in the training of STEM teachers in Kenya that cascaded down to female learners in primary schools. Unequal teacher qualification is an issue that was observed in this study with Public schools identified with a higher number of qualified teaching staff than private schools over the area of study. However, despite more professional training compared to private schools, there is the existence of teachers who do not believe in girl child performance in STEM.

\section{Conclusion and Recommendation}

Household chores can be used as contextual learning reference and manipulatives to enhance girl child engagement and performance in STEM. The majority of teachers do not use household chores as contexts for learning activity designs. The study concludes that the teaching approaches majorly employed by teachers are disadvantageous to girl child participation and performance in STEM. Experience of teachers, their gender, and professional training are observed to have a significant contribution to girl child performance. The study 
recommends an extensive nationwide investigation of the use of household chores for contextual learning with an emphasis on learning activities coupled with a policy framework to address girl child performance in STEM. The study also recommends the enhancement of gender equity in schools coupled with a staff retention framework and professional training of teachers in private schools.

\section{References}

Anderson, D., \& Nashon, S. (2007). Predators of knowledge construction: Interpreting students' metacognition in an amusement park physics program. Science Education, 91(2), 298-320.

Anderson, D., Nashon, S., Namazzi, E., Okemwa, P., Ombogo, P., Ooko, S., \& Beru, F. (2015). Transformations in Kenyan science teachers' locus of control: the influence of contextualized science and emancipated student learning. Journal of Science Teacher Education, 26(7), 599-617.

Assembly, G. (2015). Sustainable development goals. SDGs, Transforming our world: the, 2030, 338-350.

Bagaka's, J. G. (2011). The Role Of Teacher Characteristics And Practices On Upper Secondary School Students'mathematics Self-Efficacy In Nyanza Province Of Kenya: A Multilevel Analysis. International Journal of Science and Mathematics Education, 9(4), 817-842.

Beattie, A. E. (2015). A Young Child's Perspectives on Outdoor Play: A Case Study from Vancouver, British Columbia. International Journal of Early Childhood Environmental Education, 3(1), 38-53.

Benitez-Herrera, S., Spinelli, P. F., Mano, S., \& Germano, A. P. (2019). Pursuing gender equality in Astronomy in basic education: the case of the project "Girls in the Museum of Astronomy and Related Sciences". In EPJ Web of Conferences (Vol. 200, p. 02010). EDP Sciences.

Beru, F., Nashon, S., Anderson, D., Opata, P., Ooko, S., Okemwa, P., \& Wafula, S. S. (2014). Exploratory study on the impact of woodfuel use and planning strategies for its sustainability in Western Kenya.

Cheung, R., Reinhardt, T., Stone, E., \& Little, J. W. (2018). Defining teacher leadership: A framework. Phi Delta Kappan, 100(3), 38-44.

Den-Brok, P., Fisher, D., \& Scott, R. (2005). The importance of teacher interpersonal behaviour for student attitudes in Brunei primary science classes. International Journal of Science Education, 27(7), 765-779.

DU, C. R. (2016). Sustainable development goals. World Health Organization; Regional Committee ForThe Western Pacific Report.

Gömleksiz, M. N. (2012). Elementary school students' perceptions of the new science and technology curriculum by gender. Journal of Educational Technology \& Society, 15(1), 116-126.

Hooker, M. (2017). A Study on the Implementation of the" Strengthening Innovation and Practice in Secondary Education Initiative" for the Preparation of Science, Technology, English and Mathematics (STEM) Teachers in Kenya to Integrate Information and Communication Technology (ICT) in Teaching and Learning (Doctoral dissertation, Queen's University Belfast).

Hoy, A. W., \& Spero, R. B. (2005). Changes in teacher efficacy during the early years of teaching: A comparison of four measures. Teaching and teacher education, 21(4), 343-356.

Hudson, C. C., \& Whisler, V. R. (2007). Contextual teaching and learning for practitioners. Journal of Systemics, Cybernetics and Informatics, 6(4), 54-58.

Hull, D. (1993). Opening Minds, Opening Doors: The Rebirth of American Education. Center for Occupational Research and Development, PO Box 21206, Waco, TX 76702-1206..

Jia, Q., \& Ericson, D. P. (2017). Equity and access to higher education in China: Lessons from Hunan province for university admissions policy. International Journal of Educational Development, 52, 97-110.

Kashu, J. N. (2014). Survey on gender and academic performance in secondary schools in Kenya (Doctoral dissertation, University of Nairobi).

Kim, Y., Chu, H. E., \& Lim, G. (2015). Science curriculum changes and STEM education in East Asia. In Science Education in East Asia (pp. 149-226). Springer, Cham. 
Lanyasunya, P. N. (2000). Socio-cultural analysis of factors leading to girl-child school drop-out in Samburu district (Doctoral dissertation).

Lewin, K. (2015). Educational access, equity, and development: Planning to make rights realities (Vol. 98). United Nations Educational, Scientific and Cultural Organisation.

Maiyo, J. K., \& Bawane, J. (2011). Education and poverty, relationship and concerns. A case for Kenya.

Mbirianjau, L. W., Chege, F., \& Oanda, I. (2019). Exploring Enabling Interventions for Increasing Female Students' Access and Participation in Science, Technology, Engineering and Mathematics (Stem) Disciplines in Kenyan Public Universities. Msingi Journal, 1(2), 1-6.

Murphy, C., \& Beggs, J. (2001). Pupils' attitudes, perceptions and understanding of primary science: comparisons between Northern Irish and English schools.

Murphy, C., Beggs, J., \& Carlisle, K. (2003). The Impact of Co-teaching between Science Student Teachers and Primary Classroom Teachers on Children's Enjoyment and Learning of Science and Student Teacher Confidence.

Musau, L. M., \& Abere, M. J. (2015). Teacher Qualification and Students' Academic Performance in Science Mathematics and Technology Subjects in Kenya. International Journal of Educational Administration and Policy Studies, 7(3), 83-89.

Nashon, S. M. (2013). Interpreting Kenyan science teachers' views about the effect of student learning experiences on their teaching. Canadian Journal of Science, Mathematics and Technology Education, 13(3), 213-231.

Nashon, S. M., \& Anderson, D. (2013). Interpreting student views of learning experiences in a contextualized science discourse in Kenya. Journal of Research in Science Teaching, 50(4), 381-407.

Nashon, S. M., \& Madera, E. K. (2013). Instrument for assessing disposition for contextual learning of science of students in East Africa. SAGE Open, 3(3), 2158244013494862.

Nashon, S. M.; Anderson, D.; Beru, K. F.; \& Ooko, S. (2021). Contextualizing science education as an engagement strategy for the African (Kenyan) learner. In A.A. Abdi (Ed.), Critical theorizations of education (pp.116-128). Leiden, The Netherlands: Brill.

Nashon, S. M., Anderson, D., Okemwa, P., Kelonye, F., Ooko, S., \& Ombogo, P. (2015). Student learning impact on science teachers' teaching: The case of a form 3 science case in Kenya.

Ngesu, L. M., Wachira, L., Mwelu, B., \& Nyabisi, E. (2012). Critical determinants of poor performance in KCSE among girls in Arid and Semi-Arid (ASAL) regions in Kenya.

Offorma, G. C. (2009, July). Girl-child education in Africa. In Keynote Address Presented at the Conference of University WOMWNE of Africa Held in Lagos, Nigeria, 16th-19th July.

Onsongo, J. (2006). Gender inequalities in universities in Kenya. Gender inequalities in Kenya, 31-48.

Ooko, S., Beru, F. K., Nashon, S. M., \& Anderson, D. (2018, November). Contextualized Science Learning And Student's Transition From Secondary School To University: The Case Of A Public Day Secondary School In Kenya. In Proceedings of the International Conference on Future of Education (Vol. 1, No. 1, pp. 63-73).

Sithole, A., Chiyaka, E. T., McCarthy, P., Mupinga, D. M., Bucklein, B. K., \& Kibirige, J. (2017). Student Attraction, Persistence and Retention in STEM Programs: Successes and Continuing Challenges. Higher Education Studies, 7(1), 46-59.

Spencer, R. M., Sunm, M., \& Ivry, R. B. (2006). Sleep-dependent consolidation of contextual learning. Current Biology, 16(10), 1001-1005.

Thibaut, L., Ceuppens, S., De Loof, H., De Meester, J., Goovaerts, L., Struyf, A., ... \& Hellinckx, L. (2018). Integrated STEM education: A systematic review of instructional practices in secondary education. European Journal of STEM Education, 3(1), 2.

Thompson, J., \& Soyibo, K. (2002). Effects of lecture, teacher demonstrations, discussion and practical work on 10th graders' attitudes to chemistry and understanding of electrolysis. Research in Science \& Technological Education, 20(1), 25-37. 
UNESCO (2016) Global education monitoring report: education for people and planet: creating sustainable futures for all. United Nations Educational, Scientific and Cultural Organization, Paris.

Virvou, M., Katsionis, G., \& Manos, K. (2005). Combining software games with education: Evaluation of its educational effectiveness. Educational technology \& society, 8(2), 54-65.

Wajngurt, C., \& Sloan, P. J. (2019). Overcoming Gender Bias in STEM: The Effect of Adding the Arts (STEAM). InSight: A Journal of Scholarly Teaching, 14, 13-28.

Wangila, J. W. (2019). Influence Of School Leadership Practices On Girls Completion Rate In Public Primary Schools In Kimilili Sub County, Kenya. European Journal of Education Studies. 